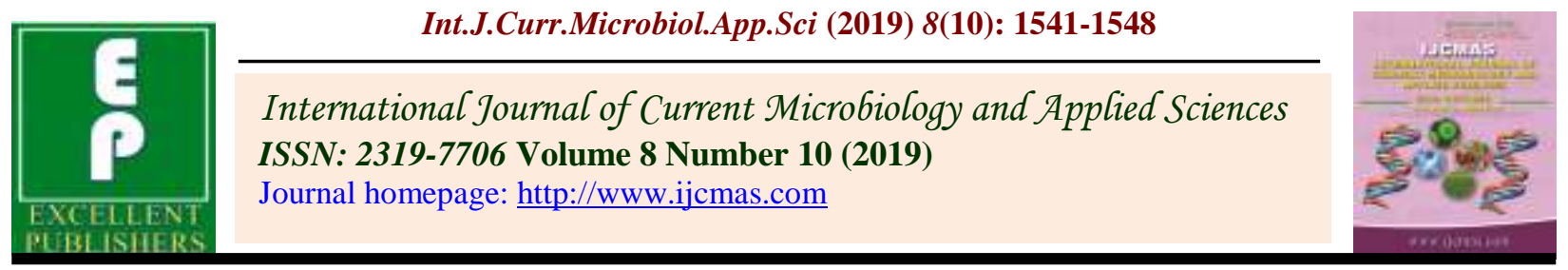

Original Research Article

https://doi.org/10.20546/ijcmas.2019.810.179

\title{
Economics of Processing of Barley Grain into Malt in the Jaipur District of Rajasthan, India
}

\author{
M. K. Choudhary ${ }^{1}$, P. S. Shekhawat ${ }^{1}$, G. Singh ${ }^{2 *}$, S. Jain ${ }^{1}$, M. Kumar ${ }^{2}$ and S. Kumari ${ }^{2}$ \\ ${ }^{1}$ Department of Agricultural Economics SKNAU Jobner Jaipur Rajasthan 303 329, India \\ ${ }^{2}$ Department of Extension Education, Agriculture University, Jodhpur, \\ Rajasthan 342 304, India \\ *Corresponding author
}

\section{A B S T R A C T}

Keywords

Processing of Barley, Malt and

Economics of

Processing

Article Info

Accepted:

12 September 2019

Available Online:

10 October 2019
The study of the economics of processing of barley into malt reveals that all the malt processing plants under study were operating at far below their intake capacity. For small size plant, total costs of running the plant, fixed, variable and raw materials costs accounted for 11.95, 8.11 and 79.94 per cent of the total costs, respectively. Whereas, for medium size plant, total costs of running the plant, fixed, variable and raw materials costs accounted for $11.30,6.30$ and 82.40 per cent of the total costs, respectively. In case of large size plant, total costs of running the plant, fixed, variable and raw materials costs accounted for 8.60, 6.46 and 84.94 per cent of the total costs, respectively. The total processing costs (including the cost of raw material) for small, medium and large size plants have been amounted 2001.32, 1942.02 and 1883.51 per quintal of barley grains, respectively. The small, medium and large size of barley processing plants got a profit of Rs 264.27, 225.17 and 283.68 per quintal of barley malt during 2017-18, respectively. Interest on term loan, and taxes and insurance charges were the main components of the total fixed cost for all the plants. Other important fixed cost components were salary of permanent staff and depreciation of the plant. Important variable cost items were electricity charges, fuel charges, packing charges, repair and maintenance charges and the temporary labour charges.

\section{Introduction}

Barley contains vitamin- A, vitamin-D, vitamin-E, and vitamin-K. Whole grain cereals are good source of the B-complex vitamins. Barley grain contains $(12.5$ per cent) moisture, (11.5 per cent) albuminoidal,
(74.0 per cent) carbohydrate, (1.3 per cent) fat, (3.9 per cent) crude fiber and (1.5 per cent) ash. Endosperm constitutes major portion of barley. It consists of starchy endosperm and a surrounding aleuronic layer. The starchy endosperm from the largest morphological part of the barley 
grain comprising 75 per cent of its weight. It forms the endosperm from which barley malt is derived, It is the prime marketable product of the plant. Barley grain is used as concentrate for feeding live-stock and poultry and a base in mushroom production. Its straw and husk are good quality roughage for cattles.

Barley straw is also used to prepare paper and cardboard. Barley crop is also used for green forage and either directly fed to the animal or used for silage. It also has immense potential as quality cereals especially for nutritional and medicinal purposes.

In India, there are very few competitors in barley malt processing. Coming to malt processing sector, application of modern technology has helped in enriching the quality of the product. It has tremendous growth opportunities in the country. The agriculture sector in general and the malt processing sector in particular have not met their potential. In this sector, production seasonality, the dominance of rain fed agriculture, high perishability of crops, lack of ready markets and low prices are some problems faced by producers.

Indian malt processing industry is rising from small scale to large one to compete with the international industries. Hence, in the competitive market it is necessary that processing operations should be cost effective. As the materials and money required for processing operations considerably bags a high cost, it is necessary to optimize the technical and economic feasibility of malt processing operations. This necessitates carrying out as a good guide planners, financial agencies and small rural entrepreneurs who wish to "malt processing', plant as a commercial viable industry.

\section{Objective}

To study the economics of processing of barley grain into malt in the study area

\section{Materials and Methods}

\section{Economics of processing of barley}

Tabular analysis was used to analyze the different aspects such as purchase barley grains, capacity utilization of processing units and costs and margin of malt processors of barley. As per the Micro, Small and Medium Enterprises Development Bill (2018), Government of India, the malt processing units were categories into three processor categories in the study area, as follows:

\section{Processing costs}

Processing costs were sum of fixed costs and variable costs incurred in the processing of barley into malt. Fixed costs constituted depreciation on building, machinery and equipments, administrative charges, insurance premium, license fees and interest on term loan. The variable costs included electricity and fuel charges, wages to labour, repair and maintenance charges, others (like advertisement, telephone) etc.

Total processing costs $=$ Fixed costs + Variable costs

\section{Processing margin}

Processing margin was worked out by subtracting the total costs of processing including cost of raw material (i.e. barley grains) from the total receipts by the processor.

Processing margin $=$ Total receipts $-($ Total processing costs + Costs of barley grains) 


\section{Results and Discussion}

\section{Economics of processing of barley}

Processing is the transformation of products from their less usable form to more usable form either for direct consumption or for creation of new products. The processing of agricultural products is essential because very few farm products such as milk, eggs, fruits and vegetables are consumed more or less directly in the form in which they are obtained by the producer-farmer. In the modern era, a greater part of the produce sold by the producer-farmer is now subject to further processing before it reaches the final consumer into a form of acceptable for consumption. At present, consumers are dependent upon processing for most of their requirements. Many technological changes have a significant impact on the standard of living of the consumers, on the economic and social organizations of society, and on the growth of trade in the country.

Processing has many advantages as it converts the raw material into finished form and thereby bringing the products one degree nearer to human consumption. Processing is important, both for the producer- sellers as well as for consumers. It increases the total revenue of the producer by regulating the supply against the prevailing demand. Processing makes it possible for the consumer to have commodities in the form liked by him. The specific advantages of the processing are:

It changes raw food and other farm products into edible, usable and palatable forms. The processing function makes it possible for us to store perishable and semi-perishable agricultural commodities which otherwise would be wasted and facilitates the use of the surplus produce of one season in another season or year. The processing activity generates employment.

Processing satisfies the needs of consumers at a lower cost. It saves the time of the consumers and relieves them of the difficulties and botheration's experienced in processing.

Processing serves as an adjunct to other marketing functions, such as transportation, storage and merchandising.

Processing widens the market.

It reduces cost of transportation and storage.

The information pertaining to the processing costs and margin help in exploring the way of increasing the efficiency of the processing plant through modernization, by utilization of the intake capacity and other methods. High fixed cost, technical competence and booms and slumps in the market were some of the limitations. These limitations restricted barley processing business only to entrepreneurs having large amount of capital at their command.

For presenting the results in a proper manner, the chapter has been divided into three sections:

Costs and margin in the processing of barley for small size industry.

Costs and margin in the processing of barley for medium size industry.

Costs and margin in the processing of barley for large size industry costs and margin in the processing of barley in small size industry

The installed capacity of the small size plant is 30,000 quintals barley grain per annum. 
The plant runs on an average for 300 days per annum. The average operational hours per day of the plant are not fixed; it depends upon availability of raw material, prices of raw material and processed products etc.

The plant has a processing capacity of 30,000 quintals per annum but only 24,000 quintals of barley grains were processed by the plant during the year 2017-2018. The cost of processing of barley by the plant was worked out on the basis of actual quantity processed during the year i.e. 24,000 quintals per annum. The costs and margin in processing of barley are given in Table 1 .

Table 1 reveals that the total costs of running the plant in processing of barley have been Rs $48,031,800$ per year. Among the total costs of running the plant, the fixed, variable and raw materials costs were estimated to be Rs 5,731,800, Rs 39,000,00 and Rs 38400000, which accounted for $11.95,8.11$ and 79.94 per cent of the total costs, respectively. The total costs of processing (including the cost of raw material) were Rs 2001.32 per quintal of barley grains. Total receipts from processing of 24,000 quintals of barley grain was Rs $54,374,400$ as against the total processing costs (including the cost of raw material) of $48,031,800$. As such the barley processing plant gets a profit of Rs 63, 42,600 in processing of 24,000 quintals of barley grains i.e. a profit of Rs 264.27 per quintal of malt.

Further, Appendix-VI shows that interest on term loan, taxes and insurance, and salary of permanent labourers were the three major cost components accounting for 79.77 per cent of the total fixed costs. The salary of permanent staff amounted to Rs 14, 00,000 per year. Taxes and insurance expenditure amounted to Rs 3,00000 per year. The interest on term loan amounted to Rs $2,872,800$ per year. The repair and maintenance charges of the plant were Rs 7, 00000 per year. The wages of temporary laborers amounted to Rs 3, 00,000 per year. The packing charges of the processed product were Rs 4, 00,000. Fuel charges (diesel) amounted to Rs 8, 00,000 per year. Miscellaneous charges (phone, fax, postal charges etc.) of the office were Rs $1,00,000$ per year.

The recovery of barley malt and barley roots was 82 per cent and 10 per cent, respectively in processing of barley grains. The GST (Goods and Service Tax) on final product (malt)@ 18 per cent is Rs 11,145,600.

Costs and margin in the processing of barley in medium size industry

The installed capacity of the medium size plant is $1,20.000$ quintals barley grains per annum. The plant runs on an average for 300 days per annum. The average operational hours per day of the plant are not fixed; it depends upon availability of raw material, prices of raw material and processed products etc.

The plant has a processing capacity of $1,20,000$ quintals per annum but only 75,000 quintals of barley grains were processed by the plant during the year 2017-2018. The cost of processing of barley by the plant was worked out on the basis of actual quantity processed during the year i.e. 75,000 quintals per annum. The costs and margin in processing of barley are given in Table 2 .

Table 2 reveals that the total costs of running the plant in processing of barley have been Rs $145,562,000$ per year. Among the total costs of running the plant, the fixed, variable and raw materials costs accounted to Rs 16,452,000, 92,000,00 and 120000000, which accounted for $11.30,6.30$ and 82.40 per cent of the total costs respectively. The total costs of processing (including the cost of raw material) were 1942.02 per quintal of barley 
grains. Total receipts from processing of 75,000 quintals of barley grain was $16,254,0000$ as against the total processing costs (including the cost of raw material) of $14,562,000$. As such the barley processing plant gets a profit of $16,888,000$ in processing of 75,000 quintals of barley grains i.e. a profit of Rs 225.17 per quintal of malt.

Further, Appendix-VII shows that interest on term loan, taxes and insurance, and salary of permanent labourers were the three major cost components accounting for 77.19 per cent of the total fixed costs. The salary of permanent staff amounted to Rs 36,00,000 per year. Taxes and insurance expenditure amounted to Rs 5,00,000 per year. Interest on term loan has been Rs 8,599,500 per year. The repair and maintenance charges of the plant were Rs 15,00,000 per year. The wages of temporary labourers amounted to Rs 4,00,000 per year. The Packing charges of the processed product were Rs 1,000,000 per year. Fuel charges (diesel) amounted to Rs 2,000,000 per year. Miscellaneous charges (phone, fax, postal charges etc.) of the office Rs $1,50,000$ per year.

The recovery of barley malt and barley roots was 82 per cent and 10 per cent, respectively in processing of barley grains. The GST (Goods and Service Tax) on final product (malt)@ 18 per cent is Rs 33,210,000.

\section{Costs and margin in the processing of barley in large size industry}

The installed capacity of the plant is $3,50,000$ quintals barley grains per annum. The plant runs on an average for 300 days per annum. The average operational hours per day of the plant are not fixed as it depends upon availability of raw material, prices of raw material and processed products etc.
The plant has a processing capacity of $3,50,000$ quintals of barley grains per annum but only 300000 quintals of barley grains were processed by the plant during the year 2017-18. The cost of processing of barley by the plant was worked out on the basis of actual quantity processed during the year that is 300000 quintals per annum. The costs and margin in processing of barley are given in Table 3.

Table 3 reveals that the total costs of running the plant in processing of barley have been 565054000 per year. Among the total costs of running the plant, the fixed, variable and raw materials costs accounted to 48654000, 36400000 and 480000000 , which accounted for $8.60,6.46$ and 84.94 per cent of the total costs respectively. The total costs of processing (including the cost of raw material) were 1883.51 per quintal of barley grains. Total receipts from processing of 3,00,000 quintals of barley grains was $6,50,160,000$ as against the total costs (including the cost of raw material) of $5,65,054,000$. As such the barley processing plant got a profit of Rs $85,106,000$ in processing of 300000 quintals of barley grains i.e. a profit of Rs 283.68 per quintal of malt.

Further, Appendix-VIII shows that interest on term loan, taxes and insurance, and salary of permanent labour of plant were the three major cost components accounting for 79.88 per cent of the total fixed costs. Interest on term loan amounted to Rs 22,869,000 per year. The taxes and insurance cost amounted Rs 2,000,000 per year. The salary of permanent staff amounted to Rs 14,00,0000 per year. The repair and maintenance charges of the plant were Rs 6,000,000 per year. Fuel and electricity charges were the two main component of the total variable cost amounted to Rs $8,000,000$ and Rs $16,000,000$ per year, respectively. The packing charges were amounted to Rs 4,000,000 per year. 
Miscellaneous charges (phone, fax, postal charges etc.) of the office Rs 4, 00,000 per year. The recovery of barley malt and barley roots was 82 per cent and 10 per cent, respectively in processing of barley grains. The GST (Goods and Service Tax) on final product (malt) @ 18 per cent is Rs 132,840,000. All types of processing plants are running in profit. But profit is less as compare as returns per rupee investment. All the sizes of processing plants small, medium and large size barley processing plants under study were operating at far below their intake capacity. For small size plant, fixed, variable and raw materials costs accounted $11.95,8.11$ and 79.95 per cent of the total costs of running the plant, respectively.

Table.1

\begin{tabular}{|c|c|c|}
\hline S.No. & $\begin{array}{l}\text { Category of } \\
\text { Processors }\end{array}$ & Investment on Plant and Machinery (in Rs) \\
\hline 1 & Small & 25 lakhs to 5 crores \\
\hline 2 & Medium & 5 crores to 10 crores \\
\hline 3 & Large & $>10$ crores \\
\hline
\end{tabular}

Table.2 Costs and Margin in Processing of Barley in Small Size Industry (Per Annum)

\begin{tabular}{|c|c|c|}
\hline S.No. & Particulars & Units \\
\hline $\mathbf{1 .}$ & Full processing capacity (Barley grains in qtls.) & $\mathbf{3 0 0 0 0}$ \\
\hline $\mathbf{2}$ & Actual processed quantity (Barley grains in qtls.) & $\mathbf{2 4 0 0 0}$ \\
\hline $\mathbf{3}$ & Processing costs & \\
\hline $\mathbf{A .}$ & Fixed costs (Rs) & $\mathbf{5 7 3 1 8 0 0}$ \\
\hline $\mathbf{B}$ & Variable costs (Rs) & $\mathbf{1 1 . 9 5})$ \\
\hline & & $\mathbf{3 9 0 0 0 0}$ \\
\hline $\mathbf{4 .}$ & Processing costs $(\mathrm{A}+\mathrm{B})$ & $\mathbf{9 6 3 1 8 0 0}$ \\
\hline $\mathbf{5 .}$ & Costs of raw material (Rs) & $\mathbf{3 8 4 0 0 0 0 0}$ \\
\hline $\mathbf{6}$ & & $\mathbf{7 9 . 9 5})$ \\
\hline $\mathbf{7 .}$ & Total costs of running the plant(3+4) & $\mathbf{4 8 0 3 1 8 0 0}$ \\
\hline $\mathbf{8 .}$ & Total costs of running the plant (RsRs/qtls) & $\mathbf{2 0 0 1 . 3 2}$ \\
\hline $\mathbf{9 .}$ & Total receipts (Rs) & $\mathbf{5 4 3 7 4 0 4 0}$ \\
\hline
\end{tabular}

Figures in parenthesis are the percentage of the total cost of running the plant 
Table.3 Costs and margin in processing of barley in medium size (Per Annum)

\begin{tabular}{|c|c|c|}
\hline S.No. & Particulars & Units \\
\hline $\mathbf{1}$ & Full processing capacity (Barley grains in qtls.) & $\mathbf{1 2 0 0 0 0}$ \\
\hline $\mathbf{2}$ & Actual processed quantity (Barley grains in qtls.) & $\mathbf{7 5 0 0 0}$ \\
\hline $\mathbf{3}$ & Processing costs & \\
\hline $\mathbf{A}$. & Fixed costs (Rs) & $\mathbf{1 6 4 5 2 0 0 0}$ \\
\hline & & $\mathbf{1 1 . 3 0}$ \\
\hline $\mathbf{B}$. & Variable costs (Rs) & $\mathbf{9 2 0 0 0 0 0}$ \\
& & $\mathbf{6 . 3 0})$ \\
\hline & Processing costs $(\mathrm{A}+\mathrm{B})$ & $\mathbf{2 5 6 5 2 0 0 0}$ \\
\hline $\mathbf{4}$ & Costs of raw materials (Rs) & $\mathbf{1 2 0 0 0 0 0 0 0}$ \\
\hline $\mathbf{5}$ & Total cost of running the plant $(3+4)$ & $\mathbf{1 4 5 5 6 2 0 0 0}$ \\
\hline $\mathbf{6}$ & Total costs of running the plant (Rs/qtls.) & $\mathbf{1 9 4 2 . 0 2}$ \\
\hline $\mathbf{7 .}$ & Total receipts (Rs) & $\mathbf{1 6 2 5 4 0 0 0 0}$ \\
\hline $\mathbf{8 .}$ & Processing margin & $\mathbf{1 6 8 8 8 0 0 0}$ \\
\hline $\mathbf{9}$ & From processed malt (Rs) $(5-3+4)$ & $\mathbf{2 2 5 . 1 7}$ \\
\hline
\end{tabular}

Figures in parenthesis are the percentage of the total costs of running the plant

Table.4 Costs and margin in processing of barley on large size industry (Per Annum)

\begin{tabular}{|c|c|c|}
\hline S.No. & Particulars & Units \\
\hline $\mathbf{1 .}$ & Full processing capacity(Barley grains in qtls.) & $\mathbf{3 5 0 0 0 0}$ \\
\hline $\mathbf{2}$ & Actual processed quantity(Barley grains in qtls.) & $\mathbf{3 0 0 0 0 0}$ \\
\hline $\mathbf{3}$ & Processing costs & \\
\hline A. & Fixed costs (Rs) & $\mathbf{4 8 6 5 4 0 0 0}$ \\
\hline & & $\mathbf{8 . 6 0})$ \\
\hline B. & Variable costs (Rs) & $\mathbf{3 6 4 0 0 0 0 0}$ \\
& & $\mathbf{6 . 4 6})$ \\
\hline & Processing costs $(\mathrm{A}+\mathrm{B})$ & $\mathbf{8 5 0 5 4 0 0 0}$ \\
\hline $\mathbf{4 .}$ & Cost of raw material (Rs) & $\mathbf{4 8 0 0 0 0 0 0 0}$ \\
\hline & Total costs of running the plant $(3+4)$ & $\mathbf{5 6 5 0 5 4 0 0 0}$ \\
\hline & Total costs of running the plant (Rs/qtls) & $\mathbf{1 8 8 3 . 5 1}$ \\
\hline $\mathbf{7 .}$ & Total receipts (Rs) & $\mathbf{6 5 0 1 6 0 0 0 0}$ \\
\hline $\mathbf{8 .}$ & Processing margin from processed malt (Rs) $(5-3+4)$ & $\mathbf{8 5 1 0 6 0 0 0}$ \\
\hline $\mathbf{9 .}$ & Processing margin $($ Rs)/qt. malt) & $\mathbf{2 8 3 . 6 8}$ \\
\hline
\end{tabular}

Figures in parenthesis are the percentage of the total costs of running the plant 
In case of medium size plant, fixed, variable and raw materials costs accounted for 11.30, 6.30 and 82.40 per cent of the total costs, respectively. Whereas, in case of large size plant, fixed, variable and raw materials costs accounted 8.60, 6.46 and 84.94 per cent of the total costs, respectively (Table 4).

The total processing costs (including the cost of raw material) for small, medium and large size plants worked out to be Rs 2001.32, 1942.02 and 1883.51 per quintal of barley grains, respectively. The small, medium and large size of barley processing plants generated a profit of Rs 264.27, 225.17 and 283.68 per quintal of barley malt during 201718 , respectively.

\section{References}

Deepak Mudgil; Sheweta Barak; Khatkar. (2014). Remove from marked Records Optimization of enzymatic hydrolysis of guar gum using response surface methodology. B.S. Journal of food science and technology (Mysore) 51 (8) 16001605.

Rezaei, R.; Khomeiri, M.; Kashaninejad, M. and Aalami, M. 2011. Effects of guar gum and arabic gum on the physicochemical, sensory and flow behaviour characteristics of frozen yoghurt. International Journal of Dairy Technology, 64(4) 563-568.

\section{How to cite this article:}

Choudhary, M. K., P. S. Shekhawat, G. Singh, S. Jain, M. Kumar and Kumari, S. 2019. Economics of Processing of Barley Grain into Malt in the Jaipur District of Rajasthan. Int.J.Curr.Microbiol.App.Sci. 8(10): 1541-1548. doi: https://doi.org/10.20546/ijcmas.2019.810.179 